This is a post-referred version of the paper published in Asia Pacific Journal of Tourism

Research, 21:11, 1155-1168, DOI:10.1080/10941665.2015.1125377

\title{
Chinese Heritage Tourists to Heritage Sites - What are the effects of heritage motivation and perceived authenticity on satisfaction?
}

Thi Hong Hai Nguyen \& Catherine Cheung

\section{ABSTRACT}

Much of the literature on authenticity is Western-centric, while little work addresses the concept in the Asian environment. The literature relating to authenticity from Asian tourists' point of view is even underdeveloped. This study therefore aims to fill the knowledge gap by investigating Chinese tourists’ perspective of authenticity. It also examines tourists' perceived authenticity as a multi-dimensional construct in a consumer-based model, the relationship with heritage motivation and tourist satisfaction. Findings indicate that Chinese tourists' perceptions of authenticity are closely related to objective and constructive authenticity. The study demonstrates that heritage motivation has a significant positive influence on perceived authenticity and that perceived authenticity has a strong ability to predict tourist satisfaction.

Keywords: Chinese tourists, authenticity, perceived authenticity, heritage tourism, Hong Kong

\section{INTRODUCTION}

China is one of the biggest source of outbound market in the world, with more than 83 million tourist departures in 2012 (World Bank, 2014; World Tourism Organization, 2013). This market has generated a total of about 110 billion US dollars in 2012 (World Tourism Organization, 2013). Nonetheless, the majority of outbound travelers from China move within the Asian region, accounting for almost 90\% of travelers in 2007 (Xie \& Li, 2009). 
This is a post-referred version of the paper published in Asia Pacific Journal of Tourism Research, 21:11, 1155-1168, DOI:10.1080/10941665.2015.1125377

Among the major Asian destinations, Hong Kong and Macau are the most popular outbound locations for mainland Chinese tourists due to geographical and political ties with the People's Republic of China (World Tourism Organization, 2014). Hong Kong and Macau are in fact the first two outbound destinations for Mainland Chinese tourists (Xie \& Li, 2009). It is important to develop tourism attractions to sustain this large source market. In a Hong Kong case study, Li and Lo (2005) identify the opportunities and constraints for heritage tourism in Hong Kong. Their study shows that there is increasing attention and interest from both government and the local public in making heritage resources for tourism resources. Recently Hong Kong aims at tourism diversification by developing heritage tourism (Hong Kong Planning Department, 2012) and offers a wide range of heritage attractions. Therefore, it is beneficial to the tourism planning to conduct this study on Chinese tourists' perception of authenticity which can assist the future development of heritage tourism in Hong Kong as well as to other Asian destinations.

The notion of authenticity has been studied since 1960s (Timothy, 2011). The theoretical concept of authenticity is however believed to be in the early stages of its conceptualization (Chronis \& Hampton, 2006). Authenticity is commonly defined as a Western cultural notion which is associated with a tourists' search for an "authentic other" (Cole, 2007; Handler, 1986; Mkono, 2013). In the book The Tourist, MacCannel's primal reflection of the concept states that the primary motivation for Western tourists to travel lies in their quest for authenticity (Taylor, 2001). The investigation of the meaning of authenticity in the Asian world seems anyhow to be lacking which merits closer attention.

The purpose of this study is to explore tourists' interpretation of authenticity through the lens of the biggest Asian market, the mainland Chinese tourists in their 
This is a post-referred version of the paper published in Asia Pacific Journal of Tourism Research, 21:11, 1155-1168, DOI:10.1080/10941665.2015.1125377

authentic heritage experiences. In heritage tourism research, motivation and satisfaction are essential topics to study heritage tourists’ behavior (Herbert, 2001; Huh, Uysal \& McCleary, 2006; Silberberg, 1995). The two factors have proved to be associated with perceived authenticity separately in previous studies (Kolar \& Zabkar, 2010; Moscardo \& Pearce, 1986; Waller \& Lea, 1998). This study presents a consumer-based model which includes heritage motivation as an antecedent and tourist satisfaction as a consequence of perceived authenticity. The relationships between these three constructs are investigated. This is the first attempt to study the relationship between heritage motivation and satisfaction with the mediating effect of perceived authenticity. The current study aims at answering the following research questions:

(1) What is authenticity to Chinese heritage tourists?

(2) How does heritage motivation influence perceived authenticity towards Chinese tourists' heritage experiences?

(3) How does perceived authenticity influence Chinese tourists' satisfaction of heritage visits?

(4) How does heritage motivation influence Chinese tourists' satisfaction of heritage visits?

(5) What is the role of perceived authenticity in the relationship between heritage motivation and tourist satisfaction?

\section{LITERATURE REVIEW}

\section{Authenticity in tourism}

The Oxford English Dictionary (2014) defines authenticity as the fact or quality of being true, real, genuine, authoritative, sincere, original, traditionally made and, philosophically, a mode of existence. The term is widely used across different 
This is a post-referred version of the paper published in Asia Pacific Journal of Tourism Research, 21:11, 1155-1168, DOI:10.1080/10941665.2015.1125377

disciplines and has been long discussed in sociology and cultural studies (Erickson, 1995). In the field of leisure and tourism, authenticity is claimed to have originated from museum studies, determining whether an object of art really is what it appears or claims to be (Wang, 2003). Later on the concept is extended to various tourism products and now it is commonly used by tourism marketing managers in managing the brand authenticity of a destination.

The definition of authenticity varies among tourism researches. Sharpley (1994) states that the concept refers to traditional culture and origins which has a sense of realness, genuineness and uniqueness. Timothy and Boyd (2003) define authenticity as being associated with presenting the past in an accurate manner. Wang (2003) identifies five approaches to define the concept of authenticity, including cognitive objectivism, constructivism, semiotics, criticism and postmodernism. The existence of different philosophical backgrounds lead to different interpretations of authenticity and results in a lack of consensus in relation to the concept. A comprehensive review of literature offered by Nguyen and Cheung (2014) indicates that there are more than a dozen types of authenticity cited in tourism studies. Among these, (1) objective, (2) constructive and (3) existential authenticity are widely used.

Objective authenticity is defined as a museum-linked view of authenticity, referring to the pure, original and genuine version of an object (Chhabra, 2012; Wang, 1999). On the contrary, constructive authenticity denotes a concept of authenticity which results from tourists' interpretations and social constructions (Wang, 1999). While these two types of authenticity are argued to be associated with objects, existential authenticity advocates a subjective version of authenticity which is irrelevant to the objects. Wang (1999) suggests this type of authenticity to be a potential existential state of being which can be activated by tourist activities. 
This is a post-referred version of the paper published in Asia Pacific Journal of Tourism Research, 21:11, 1155-1168, DOI:10.1080/10941665.2015.1125377

Tourists' perceptions of authenticity have received plenty of attention in the last decade. The main reason is the comprehension of tourists' perception of authenticity is useful to the facilitation of tourism planning and marketing (Kolar \& Zabkar, 2010; Xie \& Wall, 2002). Previous studies show that tourists have different preferences related to authenticity and that they seek for different types of authentic experiences (Chhabra, 2010; Moscardo \& Pearce, 1999; Silver, 1993; Wait, 2000). Authenticity are found to be different between tourists and local residents (Brida, Disegna, \& Osti, 2012; Mura \& Lovelock, 2009). It is thus believed that people can perceive authenticity differently and in some cases ambiguously. Hence, more research effort is required to understand the issue of tourists’ perception of authenticity.

\section{A consumer-based model of authenticity}

A consumer-based model of perceived authenticity highlights that authenticity is not a standalone concept, and should be considered in relation to its antecedents and consequences (Kolar \& Zabkar, 2010). The model was developed and subsequently tested in the context of cultural heritage tourism by Kolar and Zabkar (2010). Four constructs are the pillar of their model: cultural motivation, objective authenticity, existential authenticity and loyalty. In their European study, it reveals that cultural motivation has positive effects on objective authenticity and existential authenticity, and that these two types of authenticity directly and positively influence loyalty.

In a similar study, Zhou, Zhang and Edelheim (2013) introduce “attitude” which is a new construct to the original model and testing the model in the context of Chinese calligraphic landscape. Findings suggest that "attitude” positively affects objective authenticity and existential authenticity. Motivation has a significant positive effect on objective authenticity, yet an insignificant effect on existential authenticity. In the 
This is a post-referred version of the paper published in Asia Pacific Journal of Tourism Research, 21:11, 1155-1168, DOI:10.1080/10941665.2015.1125377

European study motivation has positive influence on both types of authenticity. Furthermore, objective and existential authenticity have direct and positive influence on loyalty in the European study whereas in the Chinese study, objective authenticity positively affect loyalty, whereas existential authenticity has an insignificant influence on loyalty. Such comparison suggests that the relationships between perceived authenticity and motivation; and perceived authenticity with loyalty are different in the European and Chinese studies.

This study attempts to develop a multi-dimensional construct of perceived authenticity derived from the three most common ideologies related to authenticity, including objectivism, constructivism and existentialism. Both antecedent and consequence of perceived authenticity are considered in the present study, namely heritage motivation and tourist satisfaction. The three constructs proposed for this study are heritage motivation, perceived authenticity and tourist satisfaction.

Previous literatures indicate that heritage tourists are motivated by various factors such as entertainment purpose, personal attachment and knowledge pursuit (Chen, 2007; Moscardo, 1996; Poria, Butler \& Airey, 2004; Prentice, 1993 and Timothy \& Boyd, 2003). However, only one dimension is considered in this study, i.e. the knowledge pursuit motive. Heritage motivation refers to a tourist's desire to learn about culture and history of the heritage site. Tourists' motivation to visit cultural and heritage sites was showed to positively influence perceived authenticity (Apostolakis, 2003; Kolar \& Zabkar, 2010). Hence, heritage motivation is proposed to be a positive antecedent of perceived authenticity.

H1: Heritage motivation positively influences perceived authenticity Furthermore, the construct of perceived authenticity should be directly linked to tourist satisfaction of their visits to heritage sites. Kolar and Zabkar (2010) consider perceived 
This is a post-referred version of the paper published in Asia Pacific Journal of Tourism Research, 21:11, 1155-1168, DOI:10.1080/10941665.2015.1125377

authenticity as similar to satisfaction, hence linked it directly to loyalty. This research disagrees in this regard and recognizes that tourist satisfaction is an accumulate evaluation of a visit/experience, in which authenticity is only a factor to be considered. Hence, the concepts of perceived authenticity and tourist satisfaction will be examined separately. Tourist satisfaction is included in the consumer-based model perceived authenticity instead of loyalty. Tourist satisfaction in this study is the overall tourists' evaluation of their visits to heritage sites. It is hypothesized to be a consequence of perceived authenticity.

H2: Perceived authenticity positively influences tourist satisfaction

Previous studies such as Devesa, Laguna and Palacios (2010), Ross and IsoAhola (1991) and Yoon and Uysal (2005) have shown an association between tourists' motivation to visit a place and their satisfaction of the visits. Hence, this present study proposes heritage motivation to positively affect tourist satisfaction.

H3: Heritage motivation positively influences tourist satisfaction

Although heritage motivation is proposed to directly influence tourist satisfaction, the relationship can be better explained by an intermediary of perceived authenticity. Tourist satisfaction is the result of a comparison between pre and post visit, which in this case refers to heritage motivation and perceived authenticity respectively. The forth hypothesis is formed as follow:

H4: Heritage motivation indirectly influences tourist satisfaction, mediated by perceived authenticity. 
This is a post-referred version of the paper published in Asia Pacific Journal of Tourism

Research, 21:11, 1155-1168, DOI:10.1080/10941665.2015.1125377

\section{METHODOLOGY}

\section{The studied population: Chinese tourists in Hong Kong}

Mainland China has been the biggest inbound market in the last decade. In 2013, Hong Kong received more than 40 million mainland Chinese visitors, accounting for $75 \%$ of total visitors' arrivals (Hong Kong Tourism Board, 2014). The number of inbound mainland Chinese visitors is also expected to grow throughout the next years (Siu, Lee \& Leung, 2013). Shopping is the most frequent activity as well as a dominant motivation of mainland Chinese to visit Hong Kong (Huang \& Hsu, 2005; Tsang, Lee \& Liu, 2014). However, Huang and Hsu (2005) suggest that shopping should not be considered as the main attraction for Chinese tourists to visit Hong Kong, and that the shopping image of the destination should not be overly emphasized for a long term. Apparently, the shopping appeal of Hong Kong has significant competitions and threats considering the fast-changing economic and commercial development situation and in mainland China. In the same study of Huang and Hsu (2005), Chinese tourists' motivations to visit Hong Kong are for knowledge enhancement, curiosity, and experiencing a different culture and lifestyle. In fact, the younger Chinese generation Y prefers travelling independently and the two most desired travel experiences are for “enjoying an exotic culture and environment” and "broadening horizons” (Jin, Lin \& Hung, 2014). The concern for culture, lifestyle and knowledge enhancement of Chinese travelers stimulates their search for real/authentic experiences, as authenticity often associates with culture, origin and history (Timothy \& Boyd, 2003; Wang, 1999)

Hong Kong has a unique colonial history and is famous for its special Eastmeet-West culture. These unique features provide a cultural image that has the potential to allure mainland visitors. Due to the rapid transformation of Hong Kong since the 
This is a post-referred version of the paper published in Asia Pacific Journal of Tourism Research, 21:11, 1155-1168, DOI:10.1080/10941665.2015.1125377

early 80s, together with a generally acknowledged strong commodification for economic purposes, most heritage sites in Hong Kong have been reconstructed on various levels. The rich cultural, nostalgic and refine environment of the city is used in this study to explore the issue of authenticity towards heritage experiences will make a significant practical contribution to urban heritage tourism development.

\section{Measurement scale development}

The measurement items for tourist motivation and satisfaction were adopted from previous literature. Heritage motivation is defined in this study as a knowledge pursuit motive, referring to the tourists' desire to learn about culture and history of the heritage site. Four measurement items of heritage motivation were adapted from Poria, Reichel and Biran (2006), as well as Kolar and Zabkar (2010). The evaluation of tourist satisfaction is suggested to be measured in multiple dimensions, it can avoid an error caused by using a single measurement item (Yoon \& Uysal, 2005). Therefore, five measurement items of tourist general satisfaction were adapted from Oliver (1980), de Rojas and Camarero (2008), and Yoon and Uysal (2005).

Several scales of perceived authenticity have been used before, such as Chhabra (2010) and Kolar and Zabkar (2010). These studies either measure the ideology of authenticity (Chhabra, 2010) or consider two dimensions of authenticity as two separate concepts (Kokar \& Zabkar, 2010). As this study examines perceived authenticity as a multi-dimensional concept, it chooses to follow the definitions of Wang (1999) on three dimensions of authenticity as a basis for the development of the measurement scale. This helps to ensure the consistency of the multi-dimensional measurement scale of perceived authenticity. A scale development procedure adopted from Churchill's (1979) is used to develop the construct of perceived authenticity. It comprises of three 
This is a post-referred version of the paper published in Asia Pacific Journal of Tourism Research, 21:11, 1155-1168, DOI:10.1080/10941665.2015.1125377

stages, in stage one (1) a set of measurement items was extracted from the conceptualization and previous measurement scales of the three main dimensions of authenticity, including objective, constructive and existential. In stage two (2) additional items were developed from in-depth interviews with heritage tourists in Hong Kong. In stage three (3) a combined set of measurement items drawn from stage 1 and 2 was sent to a panel of experts comprising of six academic professionals, to assess the representativeness and applicability of each item towards the associated construct. Finally, 21 measurement items for perceived authenticity were validated for the survey. All proposed items were measured on a 7-point Likert scale, ranging from 1 (strongly disagree) to 7 (strongly agree).

\section{Data collection}

A survey questionnaire comprised of an open-ended question designed to answer the definition of authenticity which is the first research question of this study. Respondents were requested to explain in their own words what authenticity means to them. Moreover, for the consumer-based model of authenticity, the questionnaire used 30 measurement items related to heritage motivation, perceived authenticity and satisfaction towards the visited heritage site to answer the remaining research questions. The demographics and trip characteristics of the respondents were included in the final section of the questionnaire. The questionnaire was primarily designed in English and subsequently translated into Chinese by a bilingual tourism scholar. The Chinese version of the questionnaire was reviewed and commented for revision by five other professionals and researchers who are Chinese English bilinguals.

Various rules-of-thumb have been suggested to decide the sample size of a data SEM data, such as a minimum of 100 or 200 cases (Boomsma, 1982), and 5 or 10 cases 
This is a post-referred version of the paper published in Asia Pacific Journal of Tourism Research, 21:11, 1155-1168, DOI:10.1080/10941665.2015.1125377

per parameter (Bentler \& Chou, 1987). According to Kline (2011), a typical sample size of about 200 cases is targeted in studies where SEM is used. With 30 measurement items in the current study, the minimum sample size should be 150 cases. The sample size of 200 was therefore targeted for this study.

A survey was conducted at six different popular heritage sites in Hong Kong, including the Wong Tai Sin Temple, Man Mo Temple, Po Lin Monastery, Ten Thousand Buddha Monastery, Chi Lin Nunnery and Ping Shan Heritage Trail. Chinese mainland tourists were the target population for the survey study, six Mandarin Chinese speaking undergraduate students were recruited and trained to assist the data collection at the sites. Tourists were approached and asked to fill in the questionnaires during or upon their departures from the sites. The survey was carried out from November 2013 to January 2014 and a total of 202 valid questionnaires were collected. Questionnaires which were incomplete or had the same response to all questions were considered invalid and not included in the analysis.

\section{The measurement model}

The proposed model of perceived authenticity was examined using a structural equation modeling (SEM) approach following the common related procedures. The statistical data analysis was enabled by the IBM SPSS Statistics 20 and Amos Graphics 20 computer software respectively.

First, the quantitative data was screened for outliers and missing values. A principle component analysis (PCA) was then conducted to derive the underlying dimensions of heritage motivation, perceived authenticity and tourist satisfaction. Four items were removed as they were cross loaded or their factor loadings were less than 0.5 (See end of table 1 for the removed items). As shown in Table 1, results of the PCA suggest 6 factors extracted from the remaining 25 items. The KMO statistic (0.837) and 
This is a post-referred version of the paper published in Asia Pacific Journal of Tourism Research, 21:11, 1155-1168, DOI:10.1080/10941665.2015.1125377

the results of Bartlett's Test of Sphericity ( $\chi^{2}=3127.609$ and $\left.\mathrm{p}<0.001\right)$ were well above Kaiser's (1974) minimum thresholds, indicating sampling adequacy sufficient correlations between items.

All 25 items loaded precisely on their hypothesized constructs/sub-constructs. Heritage motivation comprised of four items, while tourist satisfaction included four items. As expected, the construct of perceived authenticity has emerged to be multidimensional, comprising four dimensions: objective authenticity, constructive authenticity, existential authenticity, and comparison to expectation.

The factor loadings of all items were larger than the 0.50 minimum requirement, indicating the achievement of convergent validity (Field, 2009). Discriminant validity was also confirmed as there was no cross loading among factors found. Within each single factor, reliability was assumed as the Cronbach's alpha values were all above the 0.70 standard. The values of Cronbach's alpha If Item Deleted were also examined and showed no significant improvement if any of the items would be deleted. In sum the factor structure resulting from PCA was found to be adequate, valid and reliable for further analyses.

Table 1. Results of the principle component analysis

\begin{tabular}{|c|c|c|c|c|c|}
\hline $\begin{array}{l}\text { Component/ } \\
\text { Item }\end{array}$ & Mean & $\begin{array}{l}\text { Factor } \\
\text { loading }\end{array}$ & $\begin{array}{l}\text { Eigen- } \\
\text { value }\end{array}$ & $\begin{array}{l}\text { Item-total } \\
\text { correlation }\end{array}$ & $\begin{array}{c}\alpha / \\
\alpha \text { if item } \\
\text { deleted }\end{array}$ \\
\hline Heritage Motivation & & & 1.89 & & .90 \\
\hline Enrich personal knowledge & 5.20 & .77 & & .68 & .91 \\
\hline Learn about Hong Kong & 5.21 & .91 & & .86 & .84 \\
\hline $\begin{array}{l}\text { Learn about Hong Kong culture \& } \\
\text { heritage }\end{array}$ & 5.12 & .92 & & .84 & .85 \\
\hline Increase knowledge regarding the site & 4.99 & .83 & & .74 & .89 \\
\hline Tourist Satisfaction & & & 2.44 & & .90 \\
\hline Satisfied with the visit & 5.62 & .87 & & .78 & .87 \\
\hline Pleased that I visited this site & 5.70 & .84 & & .80 & .86 \\
\hline Meet the expectation & 5.60 & .78 & & .77 & .87 \\
\hline Worth the time and effort & 5.48 & .85 & & .77 & .88 \\
\hline $\begin{array}{l}\text { Perceived Authenticity dimension 1: } \\
\text { Objective Authenticity }\end{array}$ & & & 3.53 & & .86 \\
\hline
\end{tabular}


This is a post-referred version of the paper published in Asia Pacific Journal of Tourism Research, 21:11, 1155-1168, DOI:10.1080/10941665.2015.1125377

\begin{tabular}{|c|c|c|c|c|}
\hline Represent the past of Hong Kong & 5.40 & .67 & .68 & .83 \\
\hline Kept from the actual period & 5.44 & .74 & .70 & .82 \\
\hline True to its original & 5.14 & .84 & .75 & .81 \\
\hline Verified by historians/ authorities & 5.04 & .80 & .70 & .82 \\
\hline Have documented history & 5.34 & .67 & .54 & .85 \\
\hline Old and ancient & 5.41 & .50 & .50 & .86 \\
\hline $\begin{array}{l}\text { Perceived Authenticity dimension 2: } \\
\text { Constructive Authenticity }\end{array}$ & & & & .86 \\
\hline Present idea of local culture & 5.36 & .53 & .52 & .86 \\
\hline Still in use for original purposes & 5.13 & .61 & .50 & .87 \\
\hline Represent local community & 5.18 & .87 & .81 & .81 \\
\hline Represent local ways of life & 5.22 & .90 & .80 & .81 \\
\hline Allows for interaction with local & 5.21 & .81 & .72 & .83 \\
\hline Opportunity to experience local culture & 5.50 & .70 & .60 & .85 \\
\hline $\begin{array}{l}\text { Perceived Authenticity dimension 3: } \\
\text { Existential Authenticity }\end{array}$ & & & & .85 \\
\hline Calm \& peaceful atmosphere & 5.88 & .80 & .65 & .87 \\
\hline Enjoy myself & 5.85 & .85 & .78 & .75 \\
\hline Feel relaxed & 6.00 & .88 & .75 & .77 \\
\hline $\begin{array}{l}\text { Perceived Authenticity dimension 4: } \\
\text { Comparison to Expectation }\end{array}$ & & & & .79 \\
\hline Same as I expect/ imagine & 5.16 & .80 & .66 & - \\
\hline Same as I have heard & 5.36 & .78 & .66 & - \\
\hline
\end{tabular}

Kaiser-Meyer-Olkin Measure of Sampling Adequacy $(\mathrm{KMO})=0.837$

Bartlett's Test of Sphericity: Chi-Square $=3127.609 ; \mathrm{df}=300 ; \mathrm{p}<0.001$

Total variance explained $=71.0 \%$

* Four removed items include: Tourist satisfaction: Better than previous visits; Perceived authenticity: Unique religious and spiritual experience, Senses (i.e. sight, hearing, touch, smell, taste) and Strong emotion.

According to the structure resulting from the PCA, a second-order measurement model containing two first-order constructs, i.e. heritage motivation and tourist satisfaction, and a second-order construct, perceived authenticity, containing four dimensions have emerged. Results of CFA of the measurement model are shown in table 2 . The goodness-of-fit indices $\left(\chi^{2}=520.765, \mathrm{df}=264, \chi^{2} / \mathrm{df}=1.973, \mathrm{CFI}=0.914\right.$, RMSEA $=0.070$ ) provided evidence of an acceptable fit between the measurement model and the observed data (Hair, Black, Babin \& Anderson, 2010; Hu \& Bentler, 1999).

The composite reliability values of all constructs were greater than the 0.70 minimum requirement (Hair et al., 2010). Hence, the reliability of all constructs could be assumed. Convergent validity of the model was assessed through factor loadings and 
This is a post-referred version of the paper published in Asia Pacific Journal of Tourism Research, 21:11, 1155-1168, DOI:10.1080/10941665.2015.1125377

the average variance extracted (AVE). The factor loadings of most variables were larger than 0.50 and significant (t-value greater than 1.96) except existential authenticity which has factor loadings of 0.42 . Nevertheless, this value can also be considered as acceptable with the given sample size of 200 (Hair et al., 2010). The AVE values of perceived authenticity and objective authenticity were close to the critical limit of 0.50 (Hair et al., 2010). Other constructs exceeded this threshold, ranging from 0.52 to 0.71 . Accordingly, the convergent validity of the constructs was deemed as acceptable.

To obtain evidence of discriminant validity, the values of the average variance extracted (AVE) between constructs were compared to the shared variance, including the Maximum Shared Variance (MSV) and Average Shared Variance (ASV) (Hair et al., 2010). As shown in table 2, the AVE values are greater than the shared variance estimates (MSV and ASV) and hence, discriminant validity of the constructs was achieved.

Table 2. Reliability and validity of the measurement model

\begin{tabular}{llllll}
\hline $\begin{array}{l}\text { Component/ } \\
\text { Item }\end{array}$ & Loading(t-value) & AVE & CR & MSV & ASV \\
\hline Heritage Motivation & & $\mathbf{0 . 7 1}$ & $\mathbf{0 . 9 1}$ & $\mathbf{0 . 1 5}$ & $\mathbf{0 . 0 9}$ \\
Enrich personal knowledge & 0.74 & & & & \\
Learn about Hong Kong & $0.93(13.24)$ & & & & \\
Learn about Hong Kong culture \& heritage & $0.90(12.91)$ & & & & \\
Increase knowledge regarding the site & $0.79(11.34)$ & & & & \\
\hline Tourist Satisfaction & & $\mathbf{0 . 7 0}$ & $\mathbf{0 . 9 0}$ & $\mathbf{0 . 3 3}$ & $\mathbf{0 . 1 8}$ \\
Satisfied with the visit & 0.85 & & & & \\
Pleased that I visited this site & $0.87(15.9)$ & & & & \\
Meet the expectation & $0.82(13.71)$ & & & & \\
Worth the time and effort & $0.80(13.33)$ & & & & \\
\hline Perceived Authenticity & & $\mathbf{0 . 4 3}$ & $\mathbf{0 . 7 4}$ & $\mathbf{0 . 3 3}$ & $\mathbf{0 . 2 4}$ \\
$\quad$ Dimension 1: Objective Authenticity & $\mathbf{0 . 8 2}$ & $\mathbf{0 . 4 7}$ & $\mathbf{0 . 8 4}$ & & \\
Represent the past of Hong Kong & 0.77 & & & & \\
Kept from the actual period & $0.73(9.76)$ & & & & \\
True to its original & $0.69(9.16)$ & & & & \\
$\quad$ Verified by historians/ authorities & $0.71(9.64)$ & & & & \\
Have documented history & $0.60(8.07)$ & & & & \\
Old and ancient & $0.59(7.86)$ & & & &
\end{tabular}


This is a post-referred version of the paper published in Asia Pacific Journal of Tourism Research, 21:11, 1155-1168, DOI:10.1080/10941665.2015.1125377

\begin{tabular}{llll} 
Dimension 2: Constructive Authenticity & $\mathbf{0 . 5 3 ( 4 . 8 1 )}$ & $\mathbf{0 . 5 2}$ & $\mathbf{0 . 8 6}$ \\
Present idea of local culture & 0.58 & & \\
Still in use for original purposes & $0.57(6.51)$ & & \\
Represent local community & $0.87(8.24)$ & & \\
Represent local ways of life & $0.85(8.12)$ & & \\
Allows for interaction with local & $0.77(7.99)$ & & \\
Opportunity to experience local culture & $0.63(6.95)$ & & \\
Dimension 3: Existential Authenticity & $\mathbf{0 . 4 2 ( 4 . 3 1 )}$ & $\mathbf{0 . 6 8}$ & $\mathbf{0 . 8 6}$ \\
Calm \& peaceful atmosphere & 0.70 & & \\
Enjoy myself & $0.91(10.85)$ & & \\
Feel relaxed & $0.85(10.76)$ & & \\
Dimension 4: Comparison to Expectation & $\mathbf{0 . 7 7 ( 6 . 5 2 )}$ & $\mathbf{0 . 6 6}$ & $\mathbf{0 . 7 9}$ \\
Same as I expect/ imagine & 0.83 & & \\
Same as I have heard & $0.79(8.97)$ & & \\
\hline
\end{tabular}

\section{Data analysis of the structural model}

Following the confirmation of the measurement model, a structural model was built using three constructs, including one exogenous (heritage motivation) and two endogenous (perceived authenticity and tourist satisfaction), and four hypothesized theoretical relationships among the constructs. The model fit indicators $\left(\chi^{2}=520.765\right.$, $\mathrm{df}=264, \chi^{2} / \mathrm{df}=1.973, \mathrm{CFI}=0.914$, RMSEA=0.070) were within the acceptable range, indicating a good fit between the model and the observed data (Hair et al., 2010). A summary of results of the hypotheses testing is provided in table 3.

Table 3. Results of hypothesis testing

Path Standardized path
coefficients (t-value)

H1: Heritage motivation positively influences perceived authenticity.

$0.39(4.22) \quad$ Supported

H2: Perceived authenticity positively influences tourist satisfaction.

0.59 (5.35) Supported

H3: Heritage motivation positively influences tourist satisfaction.
$-0.03(-0.42)$

$0.23(3.32)$
Not

supported

H4: Heritage motivation indirectly influences tourist satisfaction, mediated by perceived authenticity.
Supported 
This is a post-referred version of the paper published in Asia Pacific Journal of Tourism Research, 21:11, 1155-1168, DOI:10.1080/10941665.2015.1125377

Three direct relationships were tested by examining the standardized regression weights of the direct paths and its related critical ratio values. As shown in Figure 1, the path coefficient from heritage motivation to perceived authenticity (H1) is found to be positive, moderate in strength (0.39) and statistically significant $(\mathrm{t}=4.22, \mathrm{p}<0.01)$, indicating that hypothesis 1 is supported. The path coefficient between perceived authenticity and tourist satisfaction (H2) is specified to be positive, rather strong (0.59) and significant $(\mathrm{t}=5.35, \mathrm{p}<0.01)$, suggesting that hypothesis 2 is supported. The path coefficient between heritage motivation and tourist satisfaction (H3) is found to be statistically insignificant $(\mathrm{t}=-0.42, \mathrm{p}>0.01)$, indicating that hypothesis 3 is not supported.

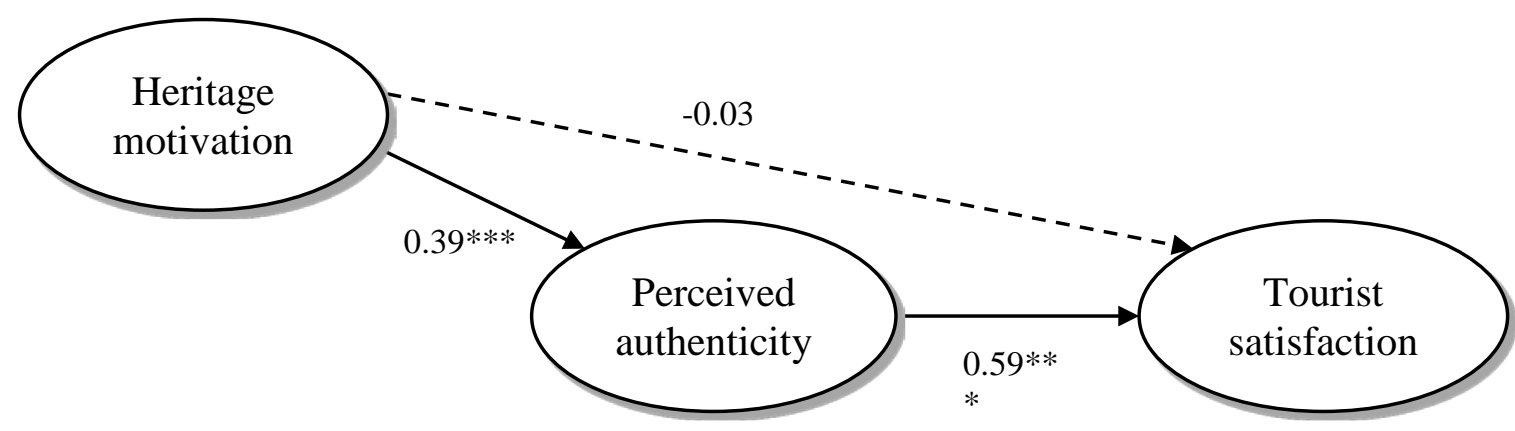

Figure 1. Structural Model Testing with the Estimated Path Coefficients

The mediating effect of perceived authenticity on the relationship between heritage motivation and tourist satisfaction (H4) was examined using a Sobel test (Baron \& Kenny, 1986; MacKinnon, Warsi, \& Dwyer, 1995; Preacher \& Hayes, 2004). MacKinnon et al.'s (1995) suggest the formula to calculate the indirect effect as follow: indirect effect $=\mathrm{a}^{*} \mathrm{~b}$ ( $\mathrm{a}$ is unstandardized regression coefficient for the association between independent variable and mediator, and $\mathrm{b}$ is unstandardized coefficient for the association between the mediator and the dependent variable). Significant level is calculated by the following formula: $z$-value $=a^{*} b / \operatorname{SQRT}\left(b^{2 *} S_{\mathrm{a}}{ }^{2}+a^{2 *} s_{\mathrm{b}}{ }^{2}\right)\left(s_{\mathrm{a}}\right.$ is standard error of a, and $s_{\mathrm{b}}$ is standard error of $\mathrm{b}$ ). These estimations were facilitated by Preacher's (2015) calculation tool. The mediating effect of perceived authenticity was 
This is a post-referred version of the paper published in Asia Pacific Journal of Tourism Research, 21:11, 1155-1168, DOI:10.1080/10941665.2015.1125377

found to be significant $(\mathrm{z}=3.32)$. However, heritage motivation indirectly influences tourist satisfaction, mediated by perceived authenticity resulted as rather weak (0.23).

\section{FINDINGS AND DISCUSSIONS}

\section{Exploring the concept of Authenticity}

The study attempts to define authenticity among Chinese heritage tourists, an openended question for respondents to explain the term authenticity in their own words was designed. A total of 98 responses were collected for this question, accounting for $48.5 \%$ of the total respondents received. Most respondents described the term in key words or short phrases. All responses were recorded and categorized according to accuracy and relevance. A summary of all responses is shown in table 4 .

Table 4. Chinese Tourists’ Depiction of Authenticity

\begin{tabular}{r|c} 
Authenticity means & Number of references \\
Original & 24 \\
Reflection of the past/history & 20 \\
Preservation & 12 \\
Representation of local culture & 6 \\
Integration between the past and the present & 5 \\
Serving original purpose & 5 \\
The same & 4 \\
True & 4 \\
Typical atmosphere & 3 \\
Ancient/old & 2 \\
Intuitive sense & 2 \\
Harmony & 1 \\
Having proved by historian & 1 \\
Remove bad and keep good things & 1 \\
Intangible & 1 \\
Completeness & 1 \\
Total & $\mathbf{9 8}$ \\
\hline
\end{tabular}


This is a post-referred version of the paper published in Asia Pacific Journal of Tourism Research, 21:11, 1155-1168, DOI:10.1080/10941665.2015.1125377

The major theme found to be associated with authenticity is original. Respondents may depict authenticity as keeping a site true to its original culture, form, appearance, features, shape, image, style, etc. The preservation of culture and heritage is also linked to authenticity. Authenticity is also identified as being relevant to the representation of local culture. The survey sites are traditional Chinese heritage sites, hence, authenticity is reasonably connected with a representation of traditional Chinese culture.

Another theme that emerges to picture the concept is a reflection of the past and history. The themes of reflection of the past and history as well as the integration between the past and the present derived from this study confirm authenticity in heritage tourism is associated with the past during the heritage visit. Authentic heritage experiences is believed to be an adaption or integration into the modern life and a way of communication between the past and the present. This interpretation is somewhat in accordance with Ashworth and Tunbridge’s (1999, p.105) proposition that heritage is "the contemporary usage of the past", referring to elements of the past "in response to current needs for it”.

The themes of authenticity drawn from the data are mostly associated with objective and constructive authenticity theory, while existential authenticity does not emerges from the qualitative data. This finding suggests that Chinese tourists' understanding of authenticity is generally related to objectivist and constructivist ideologies. Their perception of authenticity to heritage sites may advocates a pure, original and genuine version of the objects of interest or/and a constructive version according to their related interpretations and social constructions (Chhabra, 2012; Wang, 1999). Interestingly, an existentialist ideology of authenticity, which refers to a potentially existential state of being, seems to be negligible for Chinese tourists when 
This is a post-referred version of the paper published in Asia Pacific Journal of Tourism Research, 21:11, 1155-1168, DOI:10.1080/10941665.2015.1125377

visiting heritage sites. This finding needs to be further verified with the quantitative data obtained from the main survey of this study. The following sections present the findings and discussion of the quantitative survey.

\section{Chinese heritage tourists' perceived authenticity}

The analysis of the measurement model from the observed data identifies four dimensions of Chinese tourists' perceived authenticity toward heritage experiences, namely (1) Objective Authenticity (2) Constructive Authenticity (3) Existential Authenticity and (4) Comparison to Expectation. Among the four dimensions, Objective Authenticity loaded the highest on perceived authenticity with a factor loading of 0.82 , follows by Comparison to Expectation with factor loading of 0.77. Constructive Authenticity and Existential Authenticity have factor loadings of 0.53 and 0.42 respectively.

The statistical findings suggest that Objective Authenticity is the most important indicator of perceived authenticity, while Existential Authenticity, in turn, is the least important. This is consistent with the qualitative findings in the previous discussion that it is rather obscure for Chinese tourists to perceive an existentialist ideology of authenticity when visiting heritage sites. The present study uses Chinese tourist samples but the results on the importance of perceived authenticity's dimensions concur with Chhabra's (2010) work on American students' preferences of different ideologies of authenticity. In measuring the three key dimensions of authenticity, American generation $\mathrm{Y}$ considers objectivism as the most important ideology to define authenticity and that the least importance is given to existentialism. Another study on several cultural heritage sites in Europe by Kolar and Zabkar (2010) reveal that objectbased authenticity has a stronger effect on loyalty than existential authenticity. Hence, 
This is a post-referred version of the paper published in Asia Pacific Journal of Tourism Research, 21:11, 1155-1168, DOI:10.1080/10941665.2015.1125377

the importance of objective authenticity is confirmed throughout American, European and Asian cultural contexts. In addition, the context of the present study which focus on tangible heritage sites may influence the intensity of Objective Authenticity. McKercher (2002) previously found that most cultural tourists' experiences in Hong Kong tend to focus on sightseeing, their experiences will be mostly object-oriented or their evaluation being mainly object-based.

Objective Authenticity refers to the authenticity of tangible heritage; Constructive Authenticity specifies the local essence of the experiences and Existential Authenticity relates to tourists' state of mind. The resulting model include these three prevailing dimensions and a new one, i.e. Comparison to Expectation. The new dimension can be explained as a fundamental behavior of tourists when perceiving toured objects or experiences. It has been proved in previous literature that tourists' perceptions are always considered in relation to expectations (Zeithaml, Bitner \& Gremler, 2009).

Tourists evaluate their perceived aspects according to what they have expected. In the service marketing literature, expectations can be defined as previous predictions or beliefs of the consumer on the results or the performance of the product in the future (Higgs, Polonsky, \& Hollick, 2005; Olson \& Dover, 1979; Woodruff, Cadotte, \& Jenkins, 1983). These expectations are formed using several sources of information such as advertisement, word of mouth communications, or past experiences. Although visitors can hardly form expectations about a service of which they have little knowledge, empirical research suggests that even customers without any prior experience do form some kind of expectations (McGill \& Iacobucci, 1992). Chandler and Costello (2002) indicate that heritage tourists are frequent users of travel information sources such as visitor centers, maps, highway signs, brochures and 
This is a post-referred version of the paper published in Asia Pacific Journal of Tourism Research, 21:11, 1155-1168, DOI:10.1080/10941665.2015.1125377

pamphlets. In this study Chinese heritage tourists may be familiar with the heritage sites from the use of travel information sources and may have formed certain expectations prior the visits Thus, this new finding reveals the significance of the evaluation of previous knowledge or expectations being part of perceived authenticity that exist in heritage visits.

\section{The effect of heritage motivation on perceived authenticity}

This study indicates that heritage motivation has a moderate positive influence on perceived authenticity, the higher heritage motivation will lead to higher perceived authenticity. As heritage motivation in this study refers to the motives to gain more knowledge about the sites as well as Hong Kong, tourists who have higher motivation are more concern on the issue of real information and experiences of the heritage visits. As the Chinese heritage tourists are more interested in the visits, they pay more attention to the sites, the local history, culture, ways of life, etc., and at the same time enjoying themselves and looking for authenticity throughout the visits. Chhabra et al. (2003) also found that those who were very interested in the Flora MacDonald Highland Games perceived it to be more authentic than their counterparts.

Furthermore, this relationship is supported by previous empirical studies such as Kolar and Zabkar (2010); Poria et al. (2003) and Waller and Lea (1998). For instance, Waller and Lea (1998) measure authenticity by a single item on a four-point scale, ranging from the least authentic to the most authentic. Kolar and Zabkar (2010) include only two major dimensions of authenticity, namely objective and existential authenticity. Their findings in structural equation modeling show that the path coefficients from cultural motivation to objective authenticity and existential 
This is a post-referred version of the paper published in Asia Pacific Journal of Tourism Research, 21:11, 1155-1168, DOI:10.1080/10941665.2015.1125377

authenticity were 0.51 and 0.23 respectively. Similar to this study heritage motivation indeed has positive effect on objective and existential authenticity.

\section{The effect of perceived authenticity on tourist satisfaction}

Tourist satisfaction is previously proposed to be a significant outcome of perceived authenticity. The findings of this study definitely demonstrate a rather strong influence of perceived authenticity on tourist satisfaction; higher perceived authenticity will lead to higher satisfaction. Perceived authenticity can be considered as an evaluative concept similar to value and quality (Kolar \& Zabkar, 2010). Thus, tourists' perceived authenticity go through an evaluative process and it is believed to make a significant contribution to their satisfaction. This relationship is also verified in previous conceptual discussions and empirical studies (Kerstetter, Confer \& Graefe, 2001; Moscardo \& Pearce, 1986; Robinson \& Clifford, 2012; Waller \& Lea, 1998; Waitt, 2000; Yang \& Wall, 2009; among others).

Previous empirical studies show support on the relationship between perceived authenticity and satisfaction conducted in different settings. Moscardo and Pearce (1986) identify a moderately strong relationship between perceived authenticity and tourist satisfaction on historical theme parks visits. In using a multivariate regression analysis, their results show a moderately strong effect of perceived authenticity on satisfaction, with a correlation of 0.53. In another study, Waller and Lea (1998) provide empirical evidence for a positive linear relationship between perceived authenticity and predicted enjoyment. Correlations between authenticity and enjoyment scores for four scenarios (i.e. seaside village, coach tour, stay with friends and campsite) by two groups of respondents (i.e. students and general public) are calculated. All correlations are positive and significant with moderate strength ranging from 0.28 to 0.47 . 
This is a post-referred version of the paper published in Asia Pacific Journal of Tourism Research, 21:11, 1155-1168, DOI:10.1080/10941665.2015.1125377

The difference in the strengths of the relationship between perceived authenticity and tourists' satisfaction may be due to the difference in the tourism types being investigated. Cultural, heritage and historical tourism settings create higher interests in authenticity, while other types of tourism, such as beach, camping or coach tours, focus more on fun, excitement and entertaining experiences. Therefore, higher tourist satisfaction is likely to be associated with authentic experiences in cultural, heritage and historical tourism rather than in other exhilarating contexts.

In conclusion, perceived authenticity was found to play a significant role in leading to tourists' satisfaction. More importantly, perceived authenticity has the potential to predict tourist satisfaction, particularly in the context of heritage tourism. Therefore from managerial point of view it is important to improve tourist satisfaction with the cooperation with heritage site curators to encourage tourists’ authentic heritage experiences.

\section{The effect of heritage motivation on tourist satisfaction}

Previous literature suggests that heritage motivation is driven by knowledge pursuit. They are to enrich personal knowledge with natural and cultural interest (Chen, 2007); to learn something new about a historical period or event, experiencing authentic elements and experiencing the historic character (Kerstetter et al., 2001); to look for education opportunities and information (Moscardo, 1996; Prentice, 1993); to learn and the willingness to learn (Poria et al., 2006; Zeppel \& Hall, 1991). These motives can lead to the satisfaction of heritage tourists. Heritage motivation in this study is strongly dominated by the knowledge factor. The Chinese heritage tourists' motives are identified by “Learn about Hong Kong”, “Enrich personal knowledge”, “Learn about Hong Kong culture and heritage”, and "Increase knowledge regarding the site”. 
This is a post-referred version of the paper published in Asia Pacific Journal of Tourism Research, 21:11, 1155-1168, DOI:10.1080/10941665.2015.1125377

Heritage motivation is hypothesized to have a direct influence on tourist satisfaction. Interestingly, this study found that the direct effect of heritage motivation on satisfaction is statistically insignificant. The Chinese heritage tourists' respondents in this study gave lower scores on the knowledge motive of the visits, however, they score highly on the general satisfaction of the visits. This can be explained by the fact that Chinese heritage tourists' motivation is not strong enough to lead to satisfaction, in particular "Increase knowledge regarding the site”. Their expectations can still be met due to the influence of perceived authenticity on their general satisfaction towards the visits. In summary, heritage motivation alone may not influence satisfaction of the heritage tourists.

The effect of heritage motivation on tourist satisfaction, mediated by perceived authenticity

Tourist satisfaction is considered as a post-experience phenomenon, referring to the evaluation of a performance or an experience. Heritage motivation alone cannot influence satisfaction without the actual lived experience. This study found the positive relationship between heritage motivation and tourists' satisfaction when mediated by perceived authenticity. Jennings and Weiler (2006) suggest two types of mediators for the tourist experience, namely personal (e.g. other tourists, tourist providers, governments, and host communities) and non-personal (e.g. signage, design, aesthetic, and environment). Perceived authenticity within the heritage experience appears to exist as a non-personal mediator which may add value to tourist satisfaction.

The indirect relationship between heritage motivation and satisfaction can be conceptually explained by the chronological process of undertaking a visit, i.e. before, during and after. While heritage motivation is formed before the visit, authenticity is 
This is a post-referred version of the paper published in Asia Pacific Journal of Tourism Research, 21:11, 1155-1168, DOI:10.1080/10941665.2015.1125377

perceived during an experience and satisfaction usually results after the visit. Perceived authenticity can substantially affect tourist satisfaction.

Authenticity is considered as an antecedent of tourist behavior in a few studies, it is being studied as an important driver, value, motive or interest (Grayson \& Martinec, 2004; Leigh, Peters, \& Shelton, 2006; Poria et al., 2006; Yeoman, Brass \& McmahonBeattie, 2007). In this study perceived authenticity can be demonstrated to be an effective mediator or evaluative construct which includes emotional and pleasurable components that can influence satisfaction.

Based on the results of the study, Chinese heritage tourists possess knowledge motives, engage in objective and constructive authenticity and are generally satisfied with the heritage visits. Goulding (2000) classified 'Existential', 'Aesthetical' and 'Social' visitors in regard to how they perceive authenticity. The characteristics of the perceived authenticity of Chinese heritage tourists in Hong Kong are said to be 'Aesthetical' and 'Social' since they are knowledge seeking and are interested to know more about the past or history. Perceived authenticity as a mediator has helped to enrich the understanding of the positive relationship between heritage motivation and satisfaction.

\section{CONCLUSION}

A comprehensive review of literature indicates that much attention has been paid to the perception of authenticity throughout the last decade (Nguyen \& Cheung, 2014). Numerous studies on this topic are conducted from different perspectives (such as tourists, curators, local residents) related to various types of tourism (including cultural/heritage tourism, medical tourism, residential tourism, film tourism, etc.) and within different geographical contexts (from small Pacific islands to famous historical 
This is a post-referred version of the paper published in Asia Pacific Journal of Tourism Research, 21:11, 1155-1168, DOI:10.1080/10941665.2015.1125377

cities in Europe). Most of these studies focus on identifying different perceptions of authenticity and the perceived authenticity of heritage sites/products. There is only a limited number of studies examining the perception of authenticity from Asian tourists' point of view. Previous research (Xie \& Wall, 2002; Xie \& Hsieh, 2012; Yang \& Wall, 2009 and Zhou et al., 2013) investigate the Chinese tourists' perception of authenticity but are insufficient to understand the complexity of this concept. The objective of this study was therefore to explore Chinese mainland tourists' perception of authenticity and to investigate their perceived authenticity as a multi-dimensional construct in a consumer-based model.

A survey was conducted with 202 Chinese mainland tourists while visiting Hong Kong heritage attractions. The analysis of the open-ended question on the understanding of authenticity indicates that Chinese Mainland tourists' perception of the concept generally denotes to an objectivist and constructivist ideology of authenticity, while existentialism seems to be less important when visiting heritage sites in Hong Kong.

In addition, the measurement model of the multi-dimensional construct of perceived authenticity specifies that objective authenticity is the most important indicator of perceived authenticity. The newly developed dimension of comparison to expectation is second important factor in this model. While constructive and existential authenticity are found to be the less important. Moreover, the establishment and testing of a consumer-based model of authenticity provides strong evidence of its important role in heritage tourism experiences. Heritage motivation is found as a significant antecedent of perceived authenticity. It also demonstrates that perceived authenticity has strong ability to predict tourist satisfaction. In addition, heritage motivation has no 
This is a post-referred version of the paper published in Asia Pacific Journal of Tourism Research, 21:11, 1155-1168, DOI:10.1080/10941665.2015.1125377

direct influence on tourist satisfaction. The relationship between the two is significant when mediated by perceived authenticity.

The results of this study should be taken into consideration of the heritage tourism context in Hong Kong. As heritage tourism centers on heritage, particularly tangible heritage as used in this case, the related evaluation of authenticity is believed to be mostly object-based, i.e. leaning towards objective and constructive authenticity, rather than being activity-based, i.e. existential authenticity. In addition, tourist satisfaction with cultural and heritage experiences is likely to be in a stronger connection with authenticity than in other contexts, such as beach and camping tourism.

The major contribution of this research is to enrich the theoretical debate and understanding on the issue of authenticity in tourism and to provide relevant information for management and marketing bodies of heritage sites. Essentially, the role of authenticity, particularly related to tourist satisfaction is evidenced and its importance in this given context is empirically proven. This suggests that heritage tourism curators should pay more attention to the issue of perceived authenticity and hence, develops appropriate site operation and marketing plans in regard to offer authentic experiences at their respective heritage sites. The significance of objectivism as a philosophy, when forming the perception of authenticity towards heritage tourism among Chinese mainland tourists is also a key indicator for curators on how to offer authentic heritage experiences. The concept of authenticity and its dimensions, especially objective authenticity, need further investigation from future studies in other Asian contexts.

Finally, a limitation of the study lies in the use of convenience sampling at six heritage sites and five of them are religious temples in Hong Kong. The particular feature of these heritage sites weakens the ability of generalization and inference to 
This is a post-referred version of the paper published in Asia Pacific Journal of Tourism Research, 21:11, 1155-1168, DOI:10.1080/10941665.2015.1125377

other populations. The results of the study should be interpreted with caution. The convenience sample may not be representative of the Chinese heritage tourist population. The results should not be generalized to all heritage visits. Future study should endeavor to seek the views of Chinese heritage tourists who have visited other heritage sites in Hong Kong or in other regions. The fairly small sample size that were obtained in this study also limit the degree of generalizability and reliability of the model. Follow-up research with adequate sample size is recommended in order to validate the model. This study examines perceived authenticity as a multi-dimensional construct which has four sub-constructs. As argued by Chin (1998), it is imperative to demonstrate a higher order model if a second order factor is embedded within a nomological network, for instance being used as a consequence and/or predictor of other variables. However, this may potentially obscure any distinctiveness among the components of the construct (Bagozzi \& Edwards, 1998). Therefore, different dimensions of perceived authenticity can be investigated separately in a future research in order to determine the distinctive roles of these dimensions in predicting tourist satisfaction. In addition, loyalty is of great concern in tourism marketing and its associations to perceived authenticity and tourist satisfaction were proven (Anderson \& Sullivan, 1993; Kolar \& Zabkar, 2010). It was yet excluded in the current model. Future study is suggested to include both satisfaction and loyalty in one model and examine the influences of perceived authenticity on the two concepts. 
This is a post-referred version of the paper published in Asia Pacific Journal of Tourism

Research, 21:11, 1155-1168, DOI:10.1080/10941665.2015.1125377

\section{References}

Anderson, E., \& Sullivan, M. W. (1993). The antecedents and consequences of customer satisfaction for firms. Marketing Science, 12(2), 125-143.

Apostolakis, A. (2003). The convergence process in heritage tourism. Annals of Tourism Research, 30(4), 795-812.

Ashworth, G. J., \& Tunbridge, J. E. (1999). Old cities, new pasts: heritage planning in selected cities of Central Europe. Geo Journal, 49(1), 105-116.

Bagozzi, R. P., \& Edwards, J. R. (1998). A general approach for representing constructs in organizational research. Organizational Research Methods, 1(1), 45-87.

Baron, R. M., \& Kenny, D. A. (1986). The moderator-mediator variable distinction in social psychological research: Conceptual, strategic, and statistical considerations. Journal of Personality and Social Psychology, 51, 1173-1182.

Bentler, P.M \& Chou, C.H. (1987). Practical issues in structural modeling. Sociological Methods \& Research, 16, 78-117.

Boomsma A. (1982). Robustness of LISREL against small sample sizes in factor analysis models. In Joreskog KG and Wold H (eds). Systems under indirection observation: Causality, structure, prediction (Part I) (pp. 149173). Amsterdam, Netherlands: North Holland.

Brida, J.G., Disegna, M., Osti, L. (2012). Perceptions of authenticity of cultural events: A host-tourist analysis. Tourism, Culture and Communication, 12 (2), 85-96.

Chandler, J. A., \& Costello, C. A. (2002). A profile of visitors at heritage tourism destinations in East Tennessee according to Plog's lifestyle and activity level preferences model. Journal of Travel Research, 41(2), 161-166.

Chen, S. J. (2007). Travel motivation of heritage tourists. In Timothy D J (ed), The Heritage Tourist Experience: Critical Essays, Volume two (pp. 49-51). England: Ashgate Publishing Ltd.

Chhabra, D. (2010). Back to the past. A sub-segment of generation Y's perceptions of authenticity. Journal of Sustainable Tourism, 18(6), 793-809.

Chhabra, D. (2012). Authenticity of the objectively authentic. Annals of Tourism Research, 39(1), 499-502.

Chin, W. W. (1998) Issues and Opinion on Structural Equation Modeling, MIS Quarterly, 22(1), vii-xvi.

Chronis, A., \& Hampton, R. D. (2006). Authenticity at Gettysburg. Advances in Consumer Research, 33, 367-369.

Churchill, G.A.Jr. (1979). A paradigm for developing better measures of marketing constructs. Journal of Marketing Research, 16, 64-73 
This is a post-referred version of the paper published in Asia Pacific Journal of Tourism

Research, 21:11, 1155-1168, DOI:10.1080/10941665.2015.1125377

Cole, S. (2007). Beyond authenticity and commodification. Annals of Tourism Research, 34(4), 943-960.

de Rojas, C. \& Camarero, C. (2008). Visitors' experience, mood and satisfaction in a heritage context: Evidence from an interpretation center. Tourism Management, 29, 525-537

Devesa, M., Laguna, M., \& Palacios, A. (2010). The role of motivation in visitor satisfaction: Empirical evidence in rural tourism. Tourism Management, 31, 547-552.

Erickson, R. J. (1995). The importance of authenticity for self and society. Symbolic Interaction, 18(2), $121-144$.

Field, A. (2009). Discovering Statistics using SPSS (3rd Ed.). London: SAGE Publications.

Goulding, C. (2000). The commodification of the past, postmodern pastiche, and the search for authentic experiences at contemporary heritage attractions. European Journal of Marketing, 34(7), 835-853.

Grayson, K., \& Martinec, R. (2004). Consumer perceptions of iconicity and indexicality and their influence on assessments of authentic market offerings. Journal of Consumer Research, 31(2), 296-312.

Hair, J. F., Black, B., Babin, B., \& Anderson, R. E. (2010). Multivariate data analysis: a global perspective. New Jersey, USA: Pearson Education Inc.

Handler, R. (1986). Authenticity. Anthropology Today, 2(1), pp. 2-4.

Herbert, D. (2001). Literary places, tourism and the heritage experience. Annals of Tourism Research, 28(2), 312-333.

Higgs, B., Polonsky, M. J., \& Hollick, M. (2005). Measuring expectations. Forecast vs. ideal expectations. Does it really matter? Journal of Retailing and Consumer Services, 12(1), 49-64.

Hong Kong Planning Department. (2012). Hong Kong 2030: Planning vision and strategy. Hong Kong: Strategic Planning Section, Hong Kong Planning Department.

Hong Kong Tourism Board. (2014). A statistical review of Hong Kong tourism 2013. Hong Kong: Research, Hong Kong Tourism Board.

Hu. L., \& Bentler, P. M. (1999). Cutoff criteria for fit indexes in covariance structure analysis: conventional criteria versus new alternatives. Structural Equation Modeling, 6(1), 1-55.

Huang, S., \& Hsu, C.H.C. (2005). Mainland Chinese residents' perceptions and motivations of visiting Hong Kong: Evidence from focus group interviews. Asia Pacific Journal of Tourism Research, 10(2), 191-205. 
This is a post-referred version of the paper published in Asia Pacific Journal of Tourism

Research, 21:11, 1155-1168, DOI:10.1080/10941665.2015.1125377

Huh, J., Uysal, M., \& McCleary, K. (2006). Cultural/heritage destinations: tourist satisfaction and market segmentation. Journal of Hospitality \& Leisure Marketing, 14(3), 81-99.

Jennings, G., and B. Weiler (2006). Mediating Meaning: Perspectives on Brokering Quality Tourism Experiences. In Quality Tourism Experiences, G. Jennings and N. Nickerson, eds. Oxford: Elsevier Butterworth-Heinemann.

Jin, T., Lin, V.S \& Hung, K. (2014). China's Generation Y's Expectation on Outbound Group Package Tour. Asia Pacific Journal of Tourism Research, 19(6), 617 644.

Kaiser, H. F. (1974). An index of factorial simplicity. Psychometrika, 39, 31-36.

Kerstetter, D. L., Confer, J. J., \& Graefe, A. R. (2001). An exploration of the specialization concept within the context of heritage tourism. Journal of Travel Research, 39(3), 267-274.

Kline, R. B. (2011). Principles and Practice of Structural Equation Modeling (3 ${ }^{\text {rd }}$ Edition). New York, NY: Guildford Press.

Kolar, T., \& Zabkar, V. (2010). A consumer-based model of authenticity: An oxymoron or the foundation of cultural heritage marketing. Tourism Management, 31(5), $652-664$.

Leigh, T. W., Peters, C., \& Shelton, J. (2006). The consumer quest for authenticity: The multiplicity of meanings within the MG subculture of consumption. Journal of Academy of Marketing Science, 34, 481-493.

Li, Y., \& Lo, R. L. B. (2005). Opportunities and constraints of heritage tourism in Hong Kong's changing cultural landscape. Tourism and Hospitality Research, 5(4), 322-345.

MacKinnon, D. P., Warsi, G., \& Dwyer, J. H. (1995). A simulation study of mediated effect measures. Multivariate Behavioral Research, 30, 41-62.

McGill, A. L., \& Iacobucci, D. (1992). The role of post-experience comparison standards in the evaluation of unfamiliar services. Advances in Consumer Research, 19, 570-578.

McKercher, B. (2002). Towards a classification of cultural tourists. International Journal of Tourism Research, 4, 29-38.

Mkono, M. (2013). African and Western tourists: Object authenticity quest? Annals of Tourism Research, 41, 195-214.

Moscardo, G. (1996). Mindful visitors: heritage and tourism. Annals of Tourism Research, 23(2), 376-397.

Moscardo, G.M., \& Pearce, P. L. (1999). Understanding ethnic tourists. Annals of Tourism Research, 26(2), 416-434. 
This is a post-referred version of the paper published in Asia Pacific Journal of Tourism

Research, 21:11, 1155-1168, DOI:10.1080/10941665.2015.1125377

Moscardo, G.M., \& Pearce, P.L. (1986). Historic theme parks: An Australian experience in authenticity. Annals of Tourism Research, 13(3), 467-479.

Mura, P., \& Lovelock, B. (2009). A not so Little Italy? Tourist and resident perceptions of authenticity in Leichhardt, Sydney. Tourism Culture \& Communication, 9(12), 29-48.

Nguyen, T.H.H \& Cheung, C. (2014). A review of authenticity research in tourism studies. The Proceedings of the 2014 TOSOK International Tourism Conference, July 2-4, Gangwon-do, Republic of Korea.

Oliver, R. L. (1980). A cognitive model of the antecedents and consequences of satisfaction decisions. Journal of Marketing Research, 17(4), 460-469.

Olson, J. C., \& Dover, P. A. (1979). Disconfirmation of consumer expectations through product trial. Journal of Applied Psychology, 64(2), pp. 179-189.

Oxford English Dictionary (2014). Authenticity. Retrieved 16 September 2014 from http://www.oed.com/view/Entry/13325?redirectedFrom=authenticity\#eid

Poria, Y., Butler, R., \& Airey, D. (2004). Links between tourists, heritage, and reasons for visiting heritage sites. Journal of Travel Research, 43(1), 19-28.

Poria, Y., Reichel, A., \& Biran, A. (2006). Heritage site perceptions and motivations to visit. Journal of Travel Research, 44, 318-326.

Preacher, K. J. (2015). Calculation for the Sobel Test: An interactive calculation tool for Mediation tests. Retrieved from http://quantpsy.org/sobel/sobel.htm.

Preacher, K. J., \& Hayes, A. F. (2004). SPSS and SAS procedures for estimating indirect effects in simple Mediation models. Behavior Research Methods, Instruments, \& Computers, 36, 717-731.

Prentice, R. (1993). Tourism and heritage attractions. London: Rouledge.

Robinson, R. N. S. \& Clifford, C. (2012). Authenticity and festival foodservice experiences. Annals of Tourism Research, 39(2), 571-600.

Ross, E. L. D., \& Iso-Ahola, S. E. (1991). Sightseeing tourists' motivation and satisfaction. Annals of Tourism Research, 18(2), 226-237.

Sharpley, R. (1994). Tourism, tourists and society. Huntingdon, Cambridgeshire: ELM Publications.

Silberberg, T. (1995). Cultural tourism and business opportunities for museums and heritage sites. Tourism Management, 16(5), 361-365.

Silver, I. (1993). Marketing authenticity in third world countries. Annals of Tourism Research, 20(2), 302-318. 
This is a post-referred version of the paper published in Asia Pacific Journal of Tourism

Research, 21:11, 1155-1168, DOI:10.1080/10941665.2015.1125377

Siu, G., Lee, L.Y.S \& Leung, D. (2013). Residents' perceptions toward the "Chinese tourist wave" in Hong Kong: An exploratory study. Asia Pacific Journal of Tourism Research, 18(5), 446-463.

Taylor, J. P. (2001). Authenticity and sincerity in tourism. Annals of Tourism Research, 28(1), 7-26.

Timothy, D. J. (2011). Cultural heritage and tourism: an introduction. Great Britain: Channel View Publications.

Timothy, D.J., \& Boyd, S.W. (2003). Heritage tourism. Harlow: Prentice Hall.

Tsang, N.K.F., Lee, L.Y.S \& Liu, C.K.L. (2014). Understanding the shopping motivation of Mainland Chinese tourists in Hong Kong. Journal of China Tourism Research, 10, 323-346.

Waitt, G. (2000). Consuming heritage: perceived historical authenticity. Annals of Tourism Research, 27(4), 835-862.

Waller, J., \& Lea, S.E.G. (1998). Seeking the real Spain? Authenticity in motivation. Annals of Tourism Research, 26(1), 110-129.

Wang, N. (1999). Rethinking authenticity in tourism experience. Annals of Tourism Research, 26(2), 349-370.

Wang, N. (2003). Authenticity. In J. Jafari (Ed), Encyclopedia of Tourism (pp.43-45). UK: Routledge

Woodruff, R. B., Cadotte, E. R., \& Jenkins, R. L. (1983). Modelling consumer satisfaction processes using experience-based norms. Journal of Marketing Research, 20(3), pp. 296-304.

World Bank (2014). International tourism, number of departures. Retrieved 07 August 2014 from http://data.worldbank.org/indicator/ST.INT.DPRT

World Tourism Organization (2013). Compendium of Tourism Statistics dataset [Electronic]. UNWTO, Madrid, data updated on 10/09/2013.

World Tourism Organization (2014). Data on Outbound Tourism (calculated on basis of arrivals in destination countries) dataset [Electronic]. UNWTO, Madrid, data updated on 13/01/2014.

Xie, P. F., \& Wall, G. (2002). Visitors' perceptions of authenticity at cultural attractions in Hainan, China. International Journal of Tourism Research, 4, 353-366.

Xie, P. F., Wu, T. \& Hsieh, H. (2012). Tourists' perception of authenticity in indigenous souvenirs in Taiwan. Journal of Travel \& Tourism Marketing, 29(5), 485-500.

Xie, Y., \& Li, M. (2009). Development of China's outbound tourism and the characteristics of its tourist flow. Journal of China Tourism Research, 5(3), 226242. 
This is a post-referred version of the paper published in Asia Pacific Journal of Tourism

Research, 21:11, 1155-1168, DOI:10.1080/10941665.2015.1125377

Yang, L., \& Wall, G. (2009). Authenticity in ethnic tourism: domestic tourists' perspectives. Current Issues in Tourism, 12(3), 235-254.

Yeoman, I. S., Brass, D., \& Mcmahon-Beattie, U. (2007). Current issue in tourism: the authentic tourist. Tourism Management, 28(4), 1128-1138.

Yoon, Y. \& Uysal, M. (2005). An examination of the effects of motivation and satisfaction on destination loyalty: a structural model. Tourism Management, 26, 45-56.

Zeithaml, V.A., Bitner, M.O., \& Gremler, D.E. (2009). Services marketing: integrating customer focus across the firm, Mcgraw-Hill/ Irwin, New York.

Zeppel, H., \& Hall, C. M. (1991). Selling art and history: cultural heritage and tourism. The Journal of Tourism Studies, 2(1), 29-45.

Zhou, Q. B., Zhang, J., Edelheim, J. R. (2013). Rethinking traditional Chinese culture: A consumer-based model regarding the authenticity of Chinese calligraphic landscape. Tourism Management, 36, 99-112. 